RELATO DE CASO

\section{RELATO DE CASO: TUMOR ESTROMAL GASTROINTESTINAL (GIST)}

\section{CASE REPORT: GASTROINTESTINAL STROMAL TUMOR (GIST)}

Alder Vieira Santana ${ }^{1}$, Melquisedeque Santos da Silva ${ }^{1}$, Nelson Matos Câmara Neto $^{1}$, Michael Chavenet ${ }^{1}$, Angélica Vieira Santana ${ }^{2}$, Silvio Alves da Silva ${ }^{3}$.

\section{RESUMO}

Introdução: O tumor estromal gastrointestinal é derivado de células intersticiais de Cajal e representa menos de $3 \%$ de todos os tumores gastrointestinais e raramente antes dos quarenta anos. Desenvolvimento: as informações do relato de caso foram obtidas por meio do prontuário, exames de imagem e laboratoriais. Ademais, os aspectos mais relevantes sobre o GIST foram abordados. Considerações finais: O GIST é um tumor raro e seu diagnóstico definitivo é por análise imunohistoquímica e o tratamento consiste na ressecção cirúrgica.

Palavras Chave: neoplasias, neoplasias gastrointestinais, tumores do estroma gastrointestinal, relatos de casos.
Citação: Santana AV, Silva MS, Neto NMC, Chavenet M, Santana AV, Silva AS. (2021) Relato de caso: tumor estromal gastrointestinal (GIST). Revista de Patologia do Tocantins, 8(1).

Instituição: ${ }^{1}$ Acadêmico do curso de Medicina da Universidade Federal do Tocantins, Palmas, Tocantins, Brasil; 2 Acadêmica de medicina da Faculdade de Medicina de Presidente Prudente FAMEPP ${ }^{3}$ Professor assistente do curso de Medicina da Universidade Federal do Tocantins.

Autor correspondente: Alder Vieira Santana. Palmas - Tocantins. Aldervieira10@yahoo.com.

http://lattes.cnpq.br/7516275205414289

Editor: Carvalho A. A. B. Medicina, Universidade Federal do Tocantins, Brasil.

Publicado: 12 de maio de 2021.

Direitos Autorais: (c) 2021 Santana et al. Este é um artigo de acesso aberto que permite o uso, a distribuição e a reprodução sem restrições em qualquer meio, desde que o autor original e a fonte sejam creditados.

Conflito de interesses: os autores declararam que não existem conflitos de interesses.

\begin{abstract}
Introduction: The gastrointestinal stromal tumor is derived from intersticial cells of Cajal and represents less than $3 \%$ of all tumors gastrointestinal e rarely before the age of forty. Development: the information in this case report was obtained through medical records, imaging and laboratory tests. In addition, the most relevant aspects of GIST were addressed. Final comments: GIST is a rare turmor and its definitive diagnosis is by immunohistochemical analysis and the treatment consists of surgical resection.
\end{abstract}

KEY WORDS: neoplasms, gastrointestinal neoplasms, gastrointestinal stromal tumor, case reports. 

DEMONSTRANDO LESÃO ELEVADA DE ASPECTO SUBMUCOSO. (FONTE: ARQUIVO PESSOAL DOS AUTORES).

O tumor estromal gastrointestinal (GIST) é derivado de células intersticiais de Cajal e é responsável por 8 em cada 10 tumores mesenquimais do trato gastrointestinal (TGI) ${ }^{1}$. Entretanto, quando consideramos todos os tipos de tumores do TGI, o GIST representa menos de $3 \%$ sendo, portanto, raro ${ }^{2}$.

Assim sendo, dentre os aspectos epidemiológicos, destacamse: o GIST acomete mais brancos, não possui preferência de sexos, ocorre por volta dos 60 anos (raramente antes dos 40 anos); localiza-se, principalmente, na porção proximal gástrica; e comumente é assintomático ${ }^{1,3}$. Ademais, sabe-se que em países orientais (China, Coreia do Sul e Taiwan) a incidência é maior que em países ocidentais (Suécia, Itália, França e EUA) ${ }^{4}$.

O GIST, geralmente, localiza-se na submucosa e muscular própria dos órgãos e, raramente, pode ampliar-se originando sintomas obstrutivos. O diagnóstico deve ser feito com quadro clínico associado a exames de imagem e, nesse sentido, a confirmação é feita por histopatológico e imuno-histoquímica. Entretanto, na prática médica, o GIST é comumente um achado de exame ${ }^{1}$.

Por fim, o tratamento depende de diversos fatores, tais como: a idade do paciente, expectativa de vida, presença de comorbidades, avaliação das possíveis sequelas funcionais, ressecabilidade e o tamanho tumoral ${ }^{3}$.

\section{DESCRIÇÃO DO CASO}

R.M.M.C., 31 anos, masculino, deu entrada na Unidade de Pronto Atendimento com relato de dor intensa em região epigástrica e hipocôndrio esquerdo, em pontada, de intensidade 07, melhora após analgésicos, sem fator de piora e acompanhada de pirose.

Além disso, referiu a presença de quadro diarreico após refeições e história prévia de perda ponderal de $4 \mathrm{~kg}$ em três meses. Ao ser questionado sobre sintomas prévios referiu possuir diagnóstico de gastrite (s.i.c.). O paciente foi medicado e houve melhora da dor e, ademais, não soube relatar se a perda ponderal estava ou não relacionada com mudanças dietéticas.

Por apresentar quadro crônico sugestivo de gastrite crônica, foi solicitado endoscopia para melhor avaliação diagnóstica. A avaliação gástrica endoscópica evidenciou pregueado de mucosa bem sistematizado e, além disso, forma, volume e elasticidade conservados.

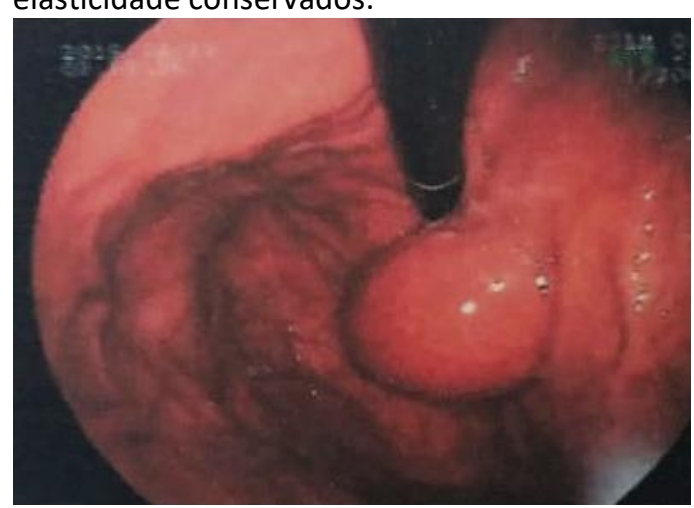

Em continuidade, a avaliação gástrica endoscópica demonstrou fundo, corpo e antro com enantema moderado de mucosas e em região subcárdica (junto à parede anterior), presença de lesão elevada de aspecto submucoso e submucosa com uma pequena ulceração em ápice de aproximadamente $4 \mathrm{~cm}$ de diâmetro e foi realizada biópsia. A principal hipótese diagnóstica para a lesão elevada de aspecto submucoso foi o GIST. A endoscopia também evidenciou pangastrite enantematosa moderada.

O resultado histopatológico evidenciou, na camada submucosa, proliferação de células fusiformes, de núcleos ovalados com cromatina frouxa, citoplasma eosinofílico amplo e que tende a se dispor em feixes enovelados. O laudo histopatológico acrescentou uma nota ressaltando a necessidade de imuno-histoquímica para melhor caracterização da histogênese da lesão e conclusão diagnóstica definitiva.

Para melhor caracterização da profundidade e presença de possíveis metástases, foi realizada tomografia computadorizada (TC). A TC evidenciou formação ovalada hipoatenuante e hipocaptante ao meio de contraste, em topografia intragástrica, insinuando-se à região de transição esofagogástrica e medindo cerca de $4.6 \times 6.1 \times 4.5 \mathrm{~cm}$. O laudo destacou a suspeita clínica de neoplasia.

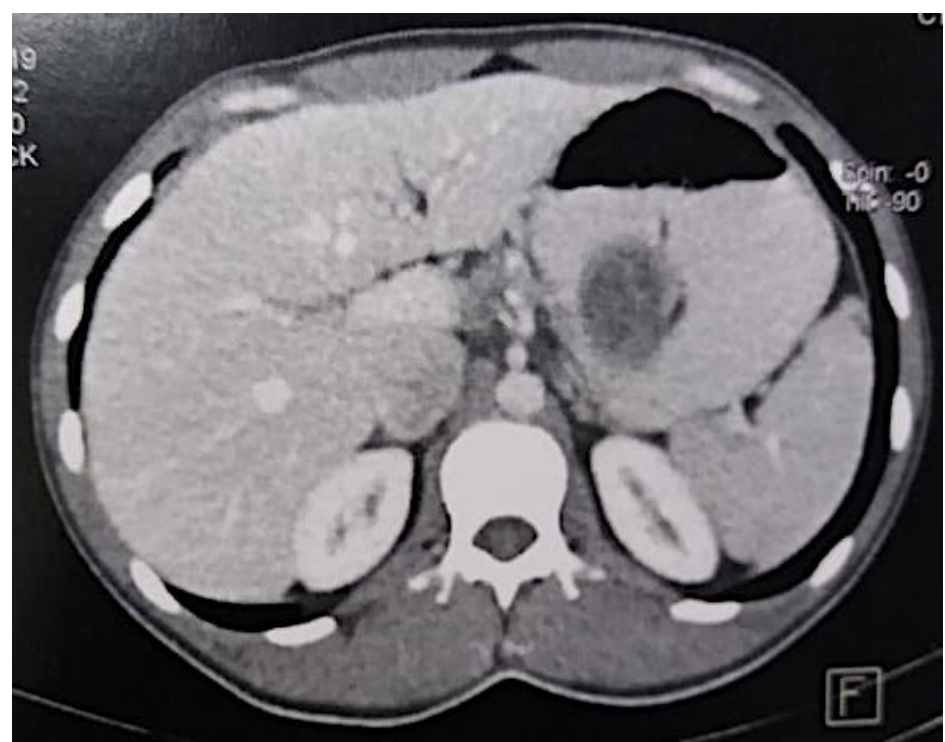

FORMAÇÃO OVALADA HIPOATENUANTE E HIPOCAPTANTE AO MEIO DE CONTRASTE, EM TOPOGRAFIA INTRAGÁSTRICA, MEDINDO CERCA DE $4.6 \times 6.1 \times 4.5$ CM. (FONTE: ARQUIVO PESSOAL DOS AUTORES).

Dessa forma, foi feita laparoscopia exploradora não sendo visualizadas alterações em órgãos intra-abdominais, exceto abaulamento sem aderências em mucosa de fundo gástrico próximo à cárdia.

Assim sendo, foi feita gastrectomia parcial com vagotomia e, assim, visualizada lesão de centro ulcerado de $6 \mathrm{~cm}$, ovalada, na submucosa, fixa em região antero-lateral de fundo gástrico, próxima à cárdia.

Nesse sentido, foi feita a ressecção da lesão gástrica e retirada de tumor da cavidade gástrica. Por fim, foi realizada a 
gastrorrafia em dois planos e retirada do tumor gástrico em saco coletor. Além disso, a peça foi enviada ao anatomopatológico.

O histopatológico destacou neoplasia mesenquimal fusocelular a esclarecer e margens cirúrgicas comprometidas. A imunohistoquímica demonstrou alta atividade mitótica, presença de focos de necrose tumoral coagulativa e imunoexpressão de CD34, CD117 e DOG1. Portanto, painel imuno-histoquímico associado aos aspectos histológicos de tumor estromal gastrointestinal (GIST).

Sabe-se que uma nova reabordagem cirúrgica foi feita e o paciente após recuperação do quadro recebeu alta e, atualmente, faz acompanhamento ambulatorial.

\section{DISCUSSÃO}

O tumor estromal gastrointestinal (GIST) é derivado de células intersticiais de Cajal e é responsável por 8 em cada 10 tumores mesenquimais do trato gastrointestinal (TGI) ${ }^{1}$.

O GIST possui como característica a presença de mutação no receptor transmembrânico tirosina quinase (c-KIT ou CD-117) ou no receptor do fator de crescimento derivado de plaquetas (gene PDGFRa). Além disso, há os do tipo selvagem, não sendo identificadas mutações nesses receptores ${ }^{1,2}$. É válido ressaltar que o KIT é expresso em $95 \%$ dos GISTs e existem outros marcadores como, por exemplo, a proteína S-100, actina e desmina ${ }^{5}$. Nesse contexto, ocorrem alterações em progenitores das células intersticiais de Cajal ou "marca-passo intestinal" no plexo mioentérico ${ }^{1,2}$. As células de Cajal expressam tais receptores e quando mutados (ativados) desencadeiam estímulos proliferativos e resistência ao controle fisiológico da morte celular programada ou apoptose ${ }^{1}$.

Na prática médica, o GIST é comumente um achado de exame e, geralmente, é assintomático. Dentre os sintomáticos, os sintomas variam de acordo com localização (estômago, intestino delgado e grosso) ${ }^{1,3}$. Além disso, os sintomas são gerais e inespecíficos, sendo manifestações comuns: dor abdominal, sangramento, sintomas dispépticos, sintomas paraneoplásicos (produção do fator de crescimento insulina like) e emagrecimento ${ }^{1,3}$. Os sintomas obstrutivos são raros, pois o GIST possui crescimento extraluminal ${ }^{6}$.

As características específicas se correlacionam com a localização, por exemplo: quando localizados no esôfago manifestam-se com disfagia; no estômago pode haver dor em epigástrio; no intestino delgado cursa com dor e massa abdominal; os colorretais com mudanças no padrão evacuatório e, por fim, os retais com sintomas relacionados à compressão vesical ${ }^{1,3}$. O GIST acomete principalmente o estômago em cerca de $55 \%$ dos casos, o duodeno em $30 \%$ e se distribui de modo homogêneo em outros locais (esôfago, cólons e reto) ${ }^{6}$. Existem vários exames de imagem que contribuem para o diagnóstico do GIST, mas a tomografia é o exame de escolha.

Assim sendo, a radiografia é inespecífica, sendo visualizados massas, deslocamento da bulha gástrica ou ar itratumoral ${ }^{1}$. A ultrassonografia de abdome total oferece resultados inespecíficos, como por exemplo, imagens císticas em região de epigástrio ${ }^{5}$. A endoscopia associada à biópsia é dificultada por sua localização submucosa ${ }^{1}$. Por outro lado, no estadiamento locorregional a USG endoscópica é o exame de escolha, pois permite amostras e a avaliação da consistência (sólida ou cística), das margens (regulares ou irregulares) e dos linfonodos acometidos (presentes ou ausentes) ${ }^{1,3}$.

Nesse contexto, o procedimento de escolha para o diagnóstico pré-operatório de pequenas lesões subepiteliais assintomáticas é realizado, principalmente, por punção aspirativa por agulha fina guiada por ultrassonografia endoscópica. Entretanto, a sensibilidade do método apresenta variações que dependem do tamanho da lesão ${ }^{2}$. O resultado histopatológico permite classifica-los em: de células fusiformes, epitelióides ou do tipo misto ${ }^{6}$.

A tomografia é o exame de escolha, pois permite visualizar sua profundidade e possíveis metástases à distância ${ }^{1}$. Dessa forma, os aspectos tomográficos mais comumente associados são: massa circunscrita, com realce heterogêneo ao contraste e de contornos lobulares e definidos ${ }^{6}$. O exame de escolha é a TC de contraste de abdome e pelve, exceto para os GISTs de acometimento retal (nesse caso, opta-se por ressonância magnética). Por fim, é válido ressaltar que o padrão de realce ao meio de contraste não é um indicativo de maior ou menor malignidade ${ }^{6}$. Ademais, há a possibilidade de áreas centrais de necrose, degeneração cística e hemorragia ${ }^{5}$.

Assim sendo, o diagnóstico definitivo é por análise imunohistoquímica ${ }^{5}$. A imuno-histoquímica é fundamental para o diagnóstico diferencial com outras patologias, tais como: schwannoma, leiomioma e leiomiossarcoma ${ }^{4}$. O tratamento depende da idade do paciente, da expectativa de vida, a presença de comorbidades, a avaliação das possíveis sequelas funcionais, a ressecabilidade e o tamanho tumoral ${ }^{3}$.

Ao avaliarmos o tamanho tumoral, deve-se ter em mente que os tumores com menos de dois centímetros e assintomáticos não são ressecados, ou seja, é feito apenas o acompanhamento ultrassonográfico endoscópico anual. Entretanto, para tumores maiores ou iguais a dois centímetros, a excisão cirúrgica está indicada devido ao maior risco de recidiva. Nesse sentido, o objetivo é fazer uma excisão com margens livres ${ }^{3}$. Logo, o tratamento consiste na ressecção cirúrgica e pelo fato de haver pseudocápsula deve ser realizada a ressecção adicional de 2-3 $\mathrm{cm}$ ao redor da tumoração para sua retirada com margens livres $(\mathrm{R} 0)^{4,6}$. Além disso, a linfadenectomia é desnecessária, pois a metástase em linfonodos é rara ${ }^{4,6}$.

Nesse contexto, em casos de doença localmente avançada, a citorredução com o uso do inibidor da tirosina quinase (IMATINIB) por 6 a 12 meses pode ser feita ${ }^{3,4}$. Por fim, o tratamento adjuvante para pacientes avançados, inoperáveis ou metastáticos consiste em uma alternativa viável e, geralmente, é feito apenas com 400mg de IMATINIB, por dia, por via oral ${ }^{3,4,6}$. Além disso, em casos resistentes a dose pode ser dobrada $(800 \mathrm{mg} / \mathrm{dia})$ ou o uso de sunitinib (fármaco considerado de 2 o linha no tratamento) pode ser considerado ${ }^{3,4}$.

Nesse sentido, alguns estudos brasileiros demonstram alta taxa de recorrências e metástases, ou seja, alta tendência para malignidade. Ademais, o fígado e o peritônio são os locais mais frequentemente acometidos por metástases. Portanto, nesses casos mais graves, o acompanhamento pode ser feito com tomografia computadorizada (TC) a cada seis meses por cinco anos. Sabe-se que após o tratamento quimioterápico pode 
haver o aparecimento de padrão cístico na tomografia e este não deve ser visto como mal prognóstico ${ }^{6}$.

Assim sendo, os principais fatores prognósticos são o local do tumor primário (sítio anatômico), a contagem mitótica e o tamanho do tumor ${ }^{2,3}$. Nesse sentido, para as lesões já ressecadas, as margens comprometidas e a ruptura tumoral contribuem para o pior prognóstico ${ }^{2}$.

Desse modo, é válido ressaltar que existem classificações que levam em consideração o tamanho e a contagem mitótica e definem a "agressividade tumoral" do GIST em: muito baixo risco, baixo risco, risco moderado e alto risco ${ }^{7}$. Assim, a depender da posição ocupada nessa classificação define-se a conduta terapêutica.

Por fim, destaca-se que este relato de caso, embora seja limitado por sua amostra (um paciente) busca contribuir para futuras pesquisas na área de tumores gastrointestinais e destaca a raridade devido à idade do paciente. Nesse contexto, novos estudos sobre o GIST devem ser realizados com o objetivo de contribuir e ampliar o conhecimento sobre sua epidemiologia.

\section{CONCLUSÃO}

O tumor estromal gastrointestinal (GIST) é derivado de células intersticiais de Cajal e consiste no principal responsável por tumores mesenquimais do trato gastrointestinal. Nesse sentido, seus sintomas são gerais $\mathbf{e}$ inespecíficos e a tomografia computadorizada é o exame de escolha, pois permite visualizar sua profundidade e possíveis metástases à distância.

Assim sendo, o diagnóstico definitivo é por análise imunohistoquímica, o tratamento consiste na ressecção cirúrgica. Logo, é preconizado como gold-standard, para o caso de GIST gástrico, a gastrectomia parcial. Dessa forma, o tratamento adjuvante para pacientes avançados, inoperáveis ou metastáticos consiste em uma alternativa viável e, geralmente, é feito com IMATINIB por via oral. Além disso, os principais fatores prognósticos são o local do tumor primário (sítio anatômico), a contagem mitótica e o tamanho do tumor.

Portanto, destaca-se a importância da compreensão dessa patologia na formação médica, e seu estudo para o aprimoramento científico e melhora do prognóstico dos pacientes acometidos. Além disso, destaca-se a contribuição epidemiológica e estudos futuros em pacientes acometidos com menos de quarenta anos.

\section{REFERÊNCIAS BIBLIOGRÁFICAS}

1. DE OLIVEIRA, Lívia dos Remédios Pamplona; DE LIMA PACE, Fábio Heleno; DE SOUZA, Aécio Flávio Meirelles. Tumores estromais do trato gastrointestinal: revisão da literatura. HU Revista, v. 37, n. 2, 2011.

2. YEGIN, Ender Gunes; DUMAN, Deniz Guney. Small EUSsuspected gastrointestinal stromal tumors of the stomach: An overview for the current state of management. Endoscopic ultrasound, v. 5, n. 2, p. 69, 2016.

3. COSTA BORGES, Thatyane et al. Tumores Estromais Gastrointestinais (GIST): Uma Revisão da Literatura. Revista de Medicina e Saúde de Brasília, v. 7, n. 2, 2018.
4. DA SILVA, Rodrigo Piltcher; MORILLOS, Matheus Bernardon; DA SILVA, Renato Azevedo. Tumor Estromal Gastrointestinal: relato de caso e revisão da literatura. RELATOS DE CASOS, v. 62, n. 2, p. 188-191, 2018.

5. DOS SANTOS PACÍFICO, Davi Sérgio et al. Clinical and Diagnostic Presentation of Gastrointestinal Stromal Tumour (GIST): A 5-Year Follow-Up. Revista Eletrônica Acervo Saúde, v. 11, n. 13, p. e996-e996, 2019.

6. MACEDO, Leonardo Lopes de et al. Tumor do estroma gastrintestinal: achados clínicos, radiológicos e anatomopatológicos. Radiol Bras, v. 40, p. 149-153, 2007.

7. FLETCHER, Christopher DM et al. Diagnosis of gastrointestinal stromal tumors: a consensus approach. International journal of surgical pathology, v. 10, n. 2, p. 81-89, 2002. 